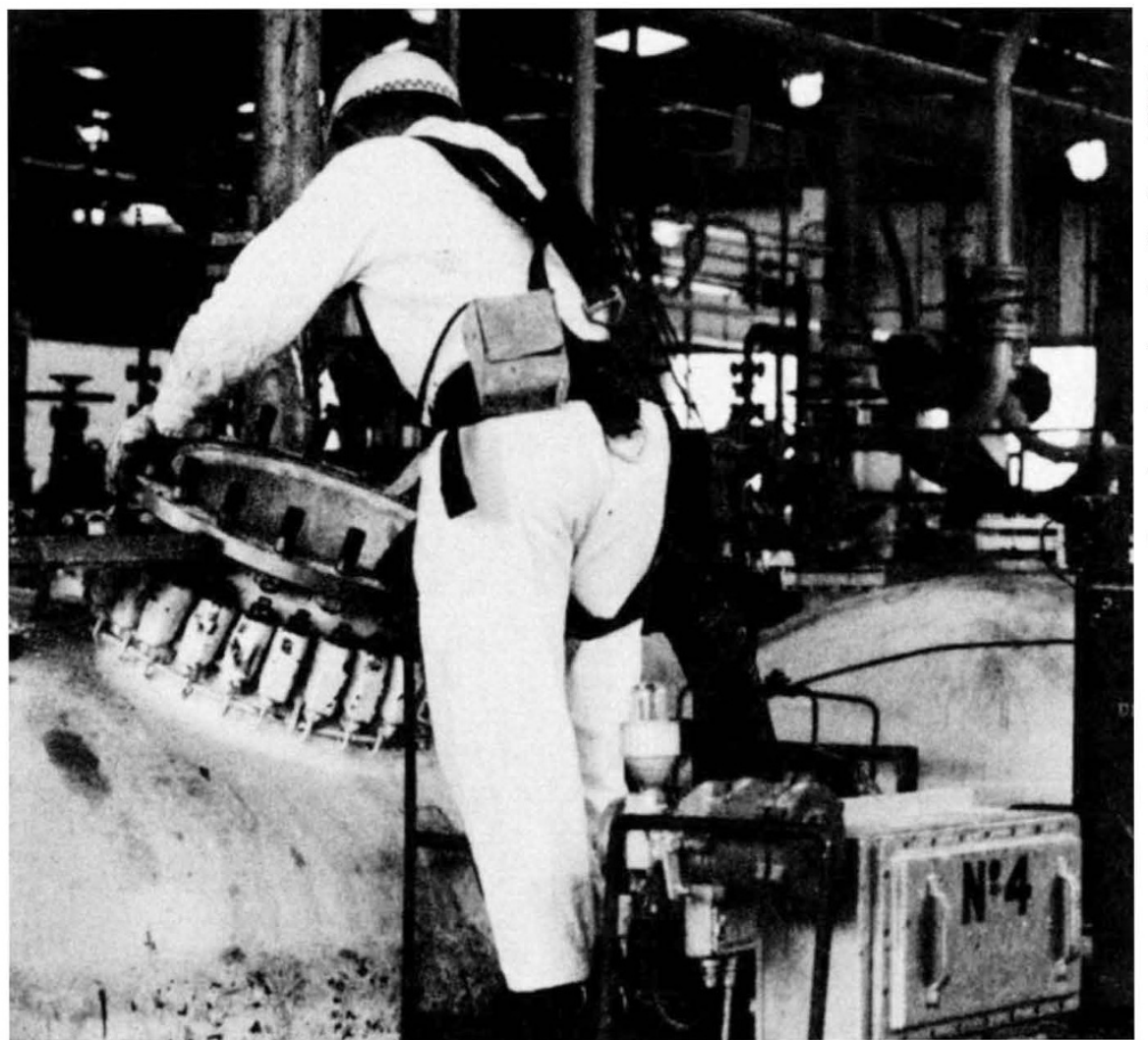

\title{
Cutting out cancers
}

THE UK Government recently accepted a Convention and a Recommendation, drawn up at last year's International Labour Conference, on 'international standards concerning the protection of workers against carcinogenic substances or agents'. Both documents will play their part in establishing some useful principles and eliminating past abuses. But the practical achievement will fall short of what is usually understood by 'international standards', and the proportion of actual cancers prevented is likely to be only a fraction of the potential number. Laura Swaffield reports.

THE terms set out by the International Labour Organisation (ILO) must be seen in context. First, the documents can apply only to substances known to be carcinogenic. Unfortunately, the probability is that most industrial carcinogens have not been identified as such.

The International Agency for Research on Cancer takes it as a rule of thumb that $80 \%$ of all cancers are environmentally induced, the most easily traced often by chemicals at work. According to the WHO, however, adequately documented cases of occupational cancer represent only a fraction of $1 \%$ of the total.

The medical profession's notorious preoccupation with finding a dramatic breakthrough cure is partly to blame. A sub-committee of the US National Cancer Advisory Board, which expressed its astonishment in March of this year that "the National Cancer Pro- gram does not appear to have accorded an adequate priority nor sense of urgency to the field of environmental carcinogenesis", estimated research expenditure on preventive work as "perhaps $10 \%$ of the budget"-a pattern which is fairly typical worldwide, and not just in cancer research.

Second, the ILO documents allow great latitude to the nations concerned - each, for instance, decides for itself which carcinogens are to be prohibited or controlled, and the nature of the controls.

Third, sheer economic reality places limits on how much can be done in industry. This is one reason why individual nations are given so much freedom to decide priorities.

The whole matter came under discussion at this year's XVIIIth International Congress on Occupational Health, held in Brighton. Dr E. Mastromatteo of the ILO said the future need was for international agreements on exposure levels to chemicals. But Mr M. El Batawi from WHO was more aware of financial, political and economic problems, especially in underdeveloped countries. International exposure levels, he said, were neither practicable nor desirable -but standardised international methodology could perhaps establish a 'doseresponse curve' along which each government could set its own limits.

Two case histories from the UK illustrate the bounds between which a line must be drawn. In 1927, ICI patented Nonox S, an anti-oxidant containing 2-naphthylamene which was marketed to the rubber industry. By 1938, the Association of British Chemical Manufacturers had accepted that there was a cancer risk from 2-naphthylamene. ICI started screening its own Nonox S workers, and by 1942 had established a proved cancer hazard for those working with the hot finished product. Only in 1949 was Nonox $\mathrm{S}$ withdrawn from sale.

The story does not end there. There was no warning to customers, and one, Dunlop, waited until the mid-1950s to set up a research unit, and until 1960 to recommend the screening of employees who had worked with Nonox $\mathbf{S}$. At one plant, screening did not begin until 1965. By 1970, some 450 cases of bladder cancer had come to light many too late for effective treatment.

As late as this year, the National Health Service (NHS) distributed a circular setting out the screening arrangements for workers and exworkers in the rubber industries. Some workers who left their jobs before screening started must still be unaware they are at risk. Meanwhile, oddly enough, the NHS does not want the circular to attract great publicity because it has "limited application", even though its implications are vast and of great discredit to all concerned.

The second case, the big occupational cancer story of 1974-75, involves vinyl chloride monomer (VCM) and shows the other side of the coin. Employees' organisations were consulted from the start when a link was discovered between VCM (used in the manufacture of PVC) and angiosarcoma, a rare liver cancer. The discovery, typically, came by accident during animal research on a VCM-linked hand condition. By early 1974, epidemiological work had turned up a possible four VCM-linked angiosarcomas in the USA, and one in the UK.

The ensuing events are something of a demonstration of ideal industrial practice. The chemical industry and government agencies (in the UK, the Employment Medical Advisory Service of the new Health and Safety Com- 
mission) got together, with trade union involvement, to find out the extent of the danger and eliminate it. The then medical adviser to the Trades Union Congress (TUC), pointed out from the start that there was no case for shutting down the polymerisation process, which annually produces 10 million tons of PVC world-wide.

By June 1974, the Department of Employment was drawing up a code of practice limiting exposure to VCM vapour to 50 parts per million with a time-weighted average of $25 \mathrm{ppm}$. As late as 1959, the prescribed threshold limit value had been 500 ppm. Significantly, the code of practice required results of atmospheric sampling to be available to workers. Today, the limit in industry is fixed at $30 \mathrm{ppm}$. (timeweighted average $10 \mathrm{ppm}$.), which is thought to be the ultimate with existing plant.

This shows what industry can do if it tries. But how does the balance sheet look? In the UK alone, $£ 13$ million has been spent since 1974 on research and alterations to plant. Four companies with a total of 500 workers are involved.

But the total of deaths in the UK now found to have been due to VCMinduced angiosarcoma is two-one a man of 71 , the other a man with a long history of liver abnormality. The worldwide score is under 40 , not all of them confirmed.

With thousands of new chemicals coming into use every year, it is only too clear that any attempt to trace and control all carcinogens, even where deaths have already occurred, would bankrupt the world chemical industry in no time. It is up to individual nations, therefore, to decide what is an acceptable risk, socially and economically.

The ILO Convention, within these limits, requires "every effort" to be made to replace or control carcinogens, all available information to be given to exposed or formerly exposed workers, relevant tests to be carried out on all workers (although there is no provision that the results be communicated to them) and government supervision throughout.

There is also an important requirement that "an appropriate system of records" be kept. Death notifications and employers' records have been instrumental in tracing VCM and Nonox $S$ workers, and record systems are the essence of occupational control where a carcinogen is discovered.

The Recommendation-a less binding formulation for signatories than the Convention-goes much further than the Convention. Most of the extras concern information: the national "competent authority" is to promote
HEALTH and safety legislation in the UK has traditionally been of the Old Testament type-detailed rules with penalties for non-compliance. This had its disadvantages. The Factory Inspectorate, for example, being hopelessly undermanned, was forced into a soft-footed approach rather than waste valuable inspecting time in court taking prosecutions which led to derisory fines even for fatal negligence.

Progress came through the Common Law which enshrines a New Testament-style duty to care for one's neighbour and leaves the practical details to the individual. It was under Common Law, for instance, that two Dunlop employees with bladder cancer were able to obtain damages in 1971 from ICI, which had no legal responsibility to them under the Factories Acts.

Claims for damages have done much to clarify the responsibilities of both employers and employees. Moreover, it was the first successful damages claim for hearing loss induced by noise at work which led to a business boom for the manufacturers of protective equipment-and has made the Department of Employment's code of practice on noise (not statutorily binding) a best-seller.

Purpose-built Old Testament legislation is usually narrow in its usefulness, and in modern industrial conditions may be out of date as soon as the ink is dry. In the UK the new Health and Safety at Work Act, which came into force this year, and unifies the Factory and Alkali Inspectorates into one Safety and Health Executive, goes as far towards the flexible New Testament approach as is possible.

It imposes a slightly more detailed duty of care on employer, employee and supplier. But old detailed regulations built up over a century remain in force, and will be expanded,

epidemiological studies, collect and disseminate all available information, produce "educational guides" for both employers and employees, and try to establish criteria for determining carcinogenicity.

Employers have a duty to seek out information, carry out studies with the aid of the competent authority, notify all affected workers and instruct them regularly. Employers' and workers' organisations both have a duty to carry out information programmes and encourage full participation by workers in control programmes.

The Nonox S story shows how necessary such measures can be, especially in countries (like the UK in the 1940s) with an undeveloped system of safety together with the more recently produced codes of practice.

Replacing the old penalties is a system of improvement and prohibition notices which oblige a manufacturer actually to shut down a process until it is made safe to the satisfaction of the relevant inspector. Arguments about notices are dealt with by the industrial tribunals, leaving the inspector to inspect and hand out notices. This puts a high price on failure to comply with the inspector's recommendations. In serious cases, the executive is free to prosecute on indictment, and the duty of care makes it reasonably clear who is to be prosecuted in each case taken. A jury verdict of guilty will lead to an unlimited fine, or perhaps even to imprisonment.

The picture elsewhere in the world mirrors the unsatisfactory state of pre-1975 UK legislation. Most EEC countries have detailed regulations about the provision of occupational health services in industrial companies. In practice, however, the carefully provided nursing services do little except routine curative work, which leaves out preventive work and epidemiology.

The USA has far-reaching and stringent safety and health laws on the Old Testament line--plus a tiny inspectorate which, it is estimated, is able to visit each factory about once every 400 years.

In the USSR, where there is no clear distinction between employer and employee in industry, the unions lack the sort of power exercised in the UK and the USA. Overall responsibility for safety and health is with government and the unions. Numerous state agencies are also involved -44 of them, for instance, in the development of the Lada (Fiat) car factory under licence from Italy. The result is often confusion and, occasionally, inaction.

law enforcement and worker participation.

But implementation could also be a tall order in many countries, and even the UK, which now probably leads the world in health and safety legislation, has confessed that it will take a considerable time to set up suitable systems.'

International cooperation on occupational health research is acknowledged to be very poor at present, quite apart from the unsatisfactory distribution of the research effort itself. The ILO's ideas on information could point the way to making use of what information there is. But it seems a pity they are tucked away in a mere Recommendation. 